\title{
Analysis of Buck Mode Realization Possibilities in Quasi-Z-Source DC-DC Converters with Voltage Doubler Rectifier
}

\author{
Janis Zakis, Ivars Rankis \\ Institute of Industrial Electronics and Electrical Engineering \\ Riga Technical University \\ Riga, Latvia \\ janis.zakis@ieee.org
}

\author{
Liisa Liivik, Andrii Chub \\ Department of Electrical Engineering \\ Tallinn University of Technology \\ Tallinn, Estonia \\ liisa.liivik@ieee.org
}

\begin{abstract}
A series resonant tank in the quasi-Z-source (qZS) DC-DC converter with a voltage doubler rectifier could significantly increase the input voltage regulation range by adding the buck mode realization possibility. This paper discusses two different control approaches of the qZS series resonant DC-DC converter in the buck mode: variable frequency control and phase shift modulation. Both methods are explained by means of steady-state analysis. To verify the theoretical background, a $200 \mathrm{~W}$ experimental prototype was built. Experimental results are compared with theoretical predictions.
\end{abstract}

Keywords-DC-DC power converter; pulse width modulation converter; resonant inverter.

\section{INTRODUCTION}

Functionality and flexibility as well as reliability of switch mode converters are the key parameters in the competition between industrial companies. For that reason, converters are designed to have as many functions as possible to achieve universal product requirements without reducing basic advantages and complicating their basic circuit diagram.

Numerous studies have described the advantages of impedance source inverters, highlighting their reliability and simplicity, as step-up converters are mainly intended for renewable energy sources [1], [2]. Fig. 1 presents the quasi-Zsource (qZS) based step-up DC-DC converter first proposed in [3]. It consists of the qZS network, an inverter, an isolation transformer and a voltage doubler rectifier (VDR). If the input voltage is equal to the rated DC-link voltage $\left(U_{1}=U_{D C}\right)$, then the inverter $\left(S_{1} \ldots S_{4}\right)$ works as a conventional voltage fed fullbridge DC-DC converter. If the input voltage drops below the rated DC-link voltage $\left(U_{1}<U_{D C}\right)$, the converter works in the boost mode by implementing the shoot-through switching states in the control of the inverter bridge to increase the input voltage amplitude up to the rated DC-link level.

In some cases, the output voltage provided by the distributed energy source (PV panels, wind generators or fuel cells) can be higher than required $\left(U_{1}>U_{\mathrm{DC}}\right)$ but still the load voltage of the converter should remain at the rated level. The disadvantage of such topology (Fig. 1) is an inability to operate in the step-down (buck) mode because the VDR tends to keep the output voltage on the level of the twofold transformer voltage amplitude. Buck mode could be possible if a full-bridge rectifier and LC-filter are combined on the secondary side of the converter [8], [9].

The aim of this paper is to study the buck function realization possibilities in the qZS DC-DC converter with a VDR in order to extend its input voltage regulation range.

\section{TOPOLOGY AND OPERATION}

Fig. 2 shows a general circuit diagram of the proposed quasi-Z-source based series resonant DC-DC converter with a VDR. It consists of the qZS network $\left(L_{l}, L_{2}, C_{l}, C_{2}, D\right)$ where both inductors are built on the same core performing magnetic coupling [4], inverter $\left(S_{1} \ldots S_{4}\right)$ and series resonant circuit $\left(L_{r}\right.$ and $C_{r}$ ) in the primary side of the isolation transformer $T R$ and $\operatorname{VDR}\left(D_{1}, D_{2}, C_{3}, C_{4}\right)$ with a load $\left(R_{l d}\right)$ on the secondary side. Implementation of series resonant elements in the transformer primary circuit was proposed in [5].

This topology enables three operation modes - normal, boost and buck. In the normal operation mode when the input voltage $U_{l}$ is nominal and equal to the required DC-link voltage $U_{D C}$, the commutation frequency of inverter switches is set the same as the resonance frequency $\left(f_{s w}=f_{r}\right)$, thus the full zero current switching (ZCS) operation of inverter switches can be achieved. In the boost operation mode when $U_{I}<U_{D C}$, the inverter is controlled by the shoot-through pulse width modulation by an overlap of active states to boost the input voltage $U_{l}$ level up to the nominal DC-link voltage level. Normal and boost operation modes were studied in detail in [6], [7].

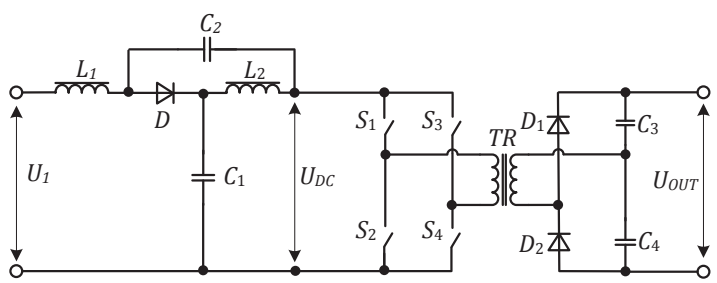

Fig. 1. Generalized topology of the qZS-based step-up DC-DC converter [3]. 


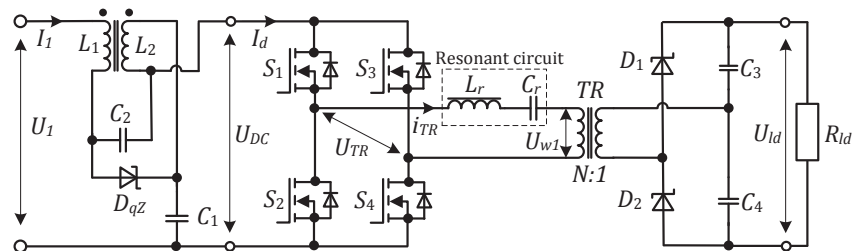

Fig. 2. General circuit diagram of the discussed qZS series resonant DC-DC converter.

If the input voltage is higher than the DC link voltage $\left(U_{I}>U_{D C}\right)$, then the proposed converter should perform a buck function. The realization possibilities of the buck function are further discussed in the next sections.

\section{Buck Mode Realization Possibilities}

Generally, two main control methods exist for the control of a series resonant DC-DC converter: variable frequency control (VFC) [10] and phase-shift modulation (PSM) [11]. Next, these two approaches will be evaluated as the buck mode control methods for the qZS based series resonant DC-DC converters.

\section{A. Variable Frequency Control}

Fig. 3 presents the generalized operation waveforms of the qZS based series resonant DC-DC converter controlled by the VFC. This control method can be performed by changing switching frequency up or down from the resonant frequency. However, the control with higher switching frequency has advantages over its counterpart with lower frequency. It allows soft-switching in the buck mode through utilization of the resonant inductor current for charging the output capacitance of the switches during the deadtime to achieve the zero voltage switching. When the switching frequency is higher than the resonant frequency, the current of one halfcycle that is conducted by one diagonal switch pair is interrupted before the end of the normal sinus wave of the transformer current $i_{T R}$. Diodes of the second switch pair of the inverter bridge start to conduct the current in the direction reverse to the qZS-network, thus creating a circulating current.

In the interval when diagonal transistors are turned off, the current of the circuit circulates through the DC source (qZS network), diodes of the inverter and primary winding of the transformer. As can be seen, the current through the resonant circuit is not interrupted and is symmetrical to the time axis. With a certain approximation, it can be accepted that the current $i_{T R}$ in that case is close to a sine wave shape, i.e. the current keeps quasi-sinusoidal properties. This mode is called the continuous conduction mode (CCM) of the series resonant converter, usually achieved through proper dimensioning of the resonant tank inductor [12].

Since the switching frequency of the inverter is higher than the resonant frequency, the rms voltage of the resonant capacitor $C_{r}$ is lower than the rms voltage of the inductor $L_{r}$, i.e. there occurs a certain rms voltage across the resonant tank $U_{\text {reac }}$. Assuming that the current in the resonant circuit is sinusoidal, the basic processes can be represented with a vector diagram (Fig. 4) in which the transformer is accepted as a linear element.

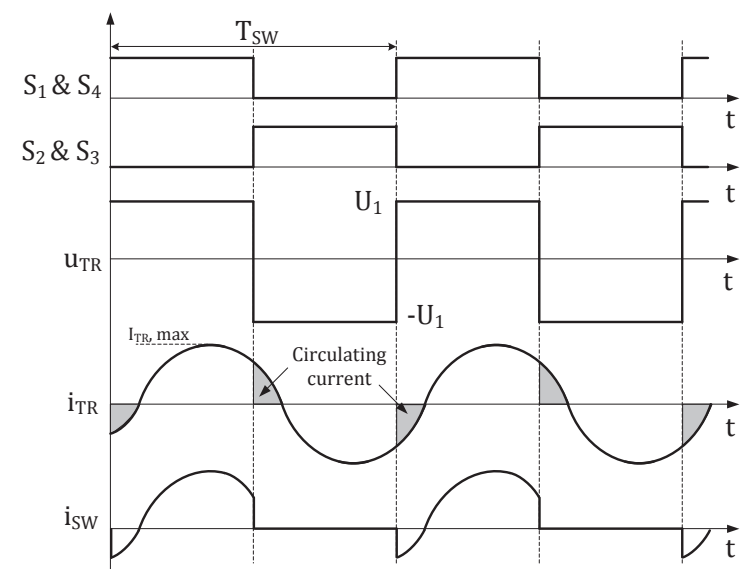

Fig. 3. Generalized operation waveforms of the VFC-controlled qZS based series resonant DC-DC converter.

The balance of resonant circuit voltages can be described from the vector diagram as

$$
U_{T R(1)}^{2}=U_{\text {reac }}^{2}+U_{w 1(1)}^{2},
$$

where $U_{T R(1)}=\frac{4 U_{1}}{\pi \sqrt{2}}$ is the rms value of the fundamental component of the bridge output voltage, while $U_{w 1(1)}=\frac{4 N \cdot U_{l d}}{2 \pi \sqrt{2}}=\frac{\sqrt{2} N \cdot U_{l d}}{\pi}$ is the rms value of the fundamental component of the primary winding voltage of the isolation transformer.

The voltage across the reactive elements can be expressed as

$$
U_{\text {reac }}=\frac{I_{r m}}{\sqrt{2}}\left(\omega_{S W} L_{r}-\frac{1}{\omega_{S W} C_{r}}\right) .
$$

The amplitude of the current in the resonant circuit is

$$
I_{r m}=4 \pi U_{1} \sqrt{\frac{\omega_{S W}^{* 2}}{4 R_{l d}^{2} N^{4} \omega_{S W}^{* 2}+\rho_{r}^{2} \pi^{4}\left(\omega_{S W}^{* 2}-1\right)^{2}}},
$$

while the load voltage is

$$
U_{l d}=4 N R_{l d} U_{1} \sqrt{\frac{\omega_{S W}^{* 2}}{4 R_{l d}^{2} N^{4} \omega_{S W}^{* 2}+\rho_{r}^{2} \pi^{4}\left(\omega_{S W}^{* 2}-1\right)^{2}}},
$$

where the normalized switching frequency can be expressed as $\omega_{S W}^{*}=\omega_{S W} / \omega_{r}$, the impedance of the resonant network $\rho_{r}=\sqrt{L_{r} / C_{r}}$ and the resonant frequency $\omega_{r}=1 / \sqrt{L_{r} \cdot C r}$.

It is evident from (4) that the output voltage can be stepped down in the buck mode simply by adjusting the switching frequency. Moreover, sensitivity of the converter to the switching frequency variations depends on the quality factor of the resonant tank, which is a ratio between the impedance of the resonant tank and the load resistance reflected to the input side. 


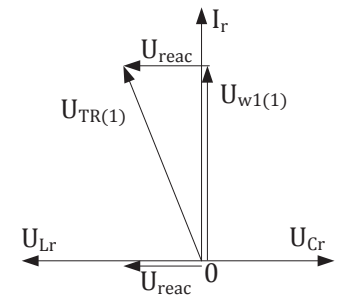

Fig. 4. Vector diagram of currents and voltages in a resonant circuit at the increased switching frequency.

\section{B. Phase Shift Modulation}

In the PSM method, the buck function is realized by overlapping the gating signals of the inverter top switches $S_{1}$ and $S_{3}$ or bottom switches $S_{2}$ and $S_{4}$. In this case, circulating currents pass through the circuits inside the inverter. Fig. 5 presents theoretical waveforms of the PSM method.

The switching frequency of the transistors is the same as the resonant frequency $\left(f_{P S M}=f_{r}\right)$. In the overlapping intervals with the shift phase $\varphi$, an input voltage of the resonant circuit is $u_{T R}=0$ but the variation of the current depends on the counter-operation of the voltage across the primary winding of the transformer $u_{w l}$. Obviously, in the course of the shift, interval current of the resonant circuit changes to a form different from the sine wave. Fundamentals of the resonant circuit current depend on both fundamentals - the input voltage $u_{T R}$ and the primary voltage of the transformer $u_{w l}$.

If the amplitude of the input voltage is $U_{l}$ but its pulse length is shortened from $\pi-\varphi$, the rms of the input voltage can be presented as

$$
U_{T R(r m s)}=\frac{2 U_{1}}{\pi} \sqrt{1+\cos \varphi}
$$

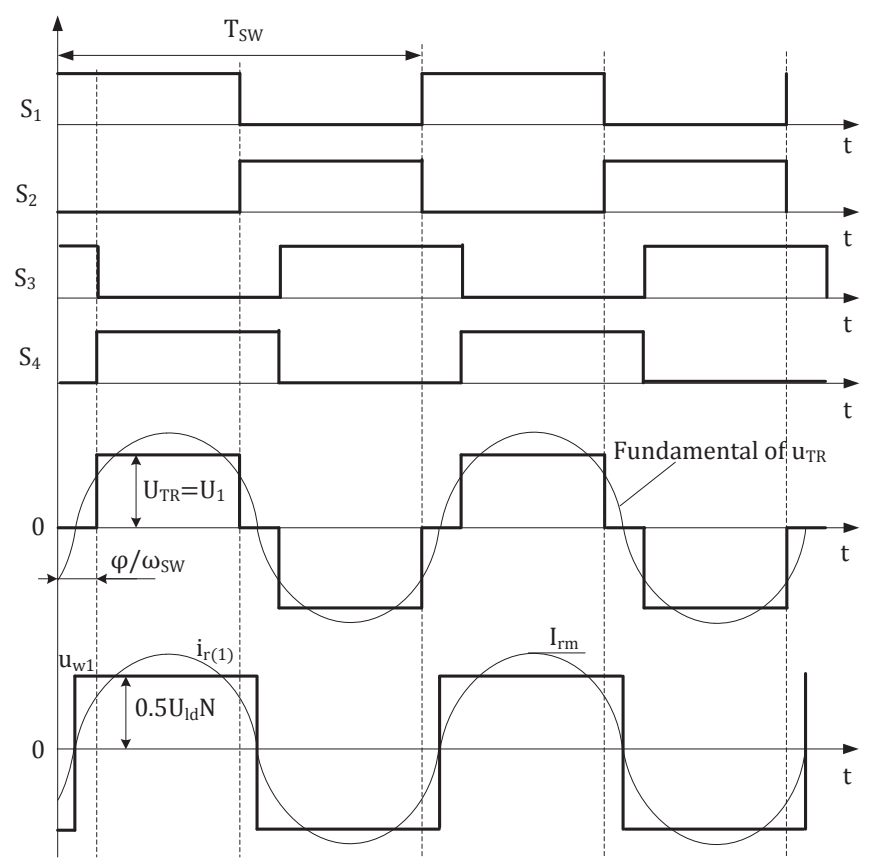

Fig. 5. Generalized operation waveforms of the PSM-controlled qZS series resonant DC-DC converter. but the rms value of the primary winding of the transformer at its rectangular shape with an amplitude $0.5 U_{l d} N$ is

$$
U_{w 1(r m s)}=\frac{2 U_{l d} N}{\pi}
$$

where $N$ is the transformer turns ratio.

Since both voltages are equal, the load voltage can be presented as

$$
U_{l d}=\frac{\sqrt{2} U_{1}}{N} \sqrt{1+\cos \varphi} .
$$

It should be noted that (8) is valid only in the case when the current in the resonant circuit is sinusoidal, i.e. the resonant converter operates in the CCM.

The amplitude of the current in a resonant circuit can be expressed as

$$
I_{r m}=\frac{\sqrt{2} \pi U_{1}}{R_{l d} N^{2}} \sqrt{1+\cos \varphi},
$$

but the current of a DC source as

$$
I_{d}=\frac{2 U_{1}(1+\cos \varphi)}{R_{l d} N^{2}} .
$$

It is shown that the PSM control allows a series resonant converter to operate with a constant switching frequency. Theoretically, the change in the load voltage depends nonlinearly on the phase shift angle $\varphi$ between the control signals of the inverter legs. Further, if the phase shift angle is $0^{\circ}$, then the output voltage is maximal, since this corresponds to the normal operation mode of the converter. Meanwhile, the output voltage decreases with the increasing phase shift angle, and reaches zero output voltage when the phase shift angle equals $180^{\circ}$.

\section{CONCEPT VERIFICATION AND DISCUSSION}

\section{A. Case Study Converter}

For the experimental verification of the theoretical background, the $200 \mathrm{~W}$ prototype of the qZS series resonant DC-DC converter was designed and assembled. General operating parameters and the components used are listed in Table I. Load resistance values presented in the table were measured from the experiment. This converter operates in the normal mode at $35 \mathrm{~V}$ at the input, when it provides $400 \mathrm{~V}$ at the output. The components of the resonant tank have been tuned to achieve $100 \mathrm{kHz}$ resonant frequency and CCM in the experimental prototype.

All calculations and measurements were performed for three operating points in the buck mode and for the normal mode, all at the constant input current. Similar operating conditions are common for renewable applications. For example, photovoltaic module integrated converter can operate in the buck mode at start-up when the panel open circuit is applied to its input. The operating points used in this study are described in Table II. Theoretical and experimental 
results for the four operating points are described, discussed and compared below to show differences between the two buck control methods.

\section{B. Theoretical Calculations}

Theoretical calculations were performed to show the differences between the two buck control methods under study. In each operating point, the power is different and thus the load resistance and the quality factor are different.

Dependence of the output voltage on the normalized switching frequency obtained from (4) for the case study converter controlled with the VFC is shown in Fig. 6 for operating points $A \ldots C$. It is evident that the switching frequency will be changing in a narrow range to stabilize the output voltage at the same level. This is due to different quality factors and output voltage values at the resonant frequency for each point. Here losses could be accounted as an additional resistance in the circuit, and thus the quality factor lower than that calculated theoretically will define the behavior of the converter. Therefore, the frequency measured experimentally has to be higher than that predicted theoretically.

TABLE I. GENERAL OPERATING PARAMETERS

\begin{tabular}{|l|c|}
\hline \multicolumn{1}{|c|}{ Operating parameters } & Value/type \\
\hline Rated power, $P$ & $200 \mathrm{~W}$ \\
\hline Input voltage, $U_{l}$ & $35 \ldots 50 \mathrm{~V}$ \\
\hline Output voltage, $U_{l d}$ & $400 \mathrm{~V}$ \\
\hline Resonant frequency, $f_{S W}$ & $100 \mathrm{kHz}$ \\
\hline \multicolumn{1}{|c|}{ Components } & \\
\hline Switch, $\mathrm{S}_{1 \ldots S_{4}}$ & Si4190ADY \\
\hline Diode, $D$ & V60D100C \\
\hline Inductors $L_{1}=L_{2}$ & $22 \mu \mathrm{H}$ \\
\hline Capacitors $C_{1}=C_{2}$ & $26.4 \mu \mathrm{F}$ \\
\hline Capacitors $C_{3}=C_{4}$ & $2.2 \mu \mathrm{F}$ \\
\hline Resonant inductor $L_{r}$ & $23.3 \mu \mathrm{H}$ \\
\hline Resonant capacitor $C_{r}$ & $93 \mu \mathrm{F}$ \\
\hline Transformer turns ratio, $N$ & $1: 6.5$ \\
\hline
\end{tabular}

TABLE II. OPERATING PoINTS USED IN THE STUdy

\begin{tabular}{|l|c|c|c|}
\hline $\begin{array}{c}\text { Operating } \\
\text { point }\end{array}$ & $\begin{array}{c}\text { Input } \\
\text { voltage, } \boldsymbol{U}_{\boldsymbol{1}}\end{array}$ & $\begin{array}{c}\text { Load } \\
\text { resistance, } \boldsymbol{R}_{\boldsymbol{l} \boldsymbol{d}}\end{array}$ & $\begin{array}{c}\text { Input } \\
\text { current, } \boldsymbol{I}_{\boldsymbol{1}}\end{array}$ \\
\hline Point $A$ & $40 \mathrm{~V}$ & $1210 \Omega$ & $4 \mathrm{~A}$ \\
\hline Point $B$ & $45 \mathrm{~V}$ & $1100 \Omega$ & $4 \mathrm{~A}$ \\
\hline Point $C$ & $50 \mathrm{~V}$ & $1012 \Omega$ & $4 \mathrm{~A}$ \\
\hline Point $D$ & $35 \mathrm{~V}$ & $1370 \Omega$ & $4 \mathrm{~A}$ \\
\hline
\end{tabular}

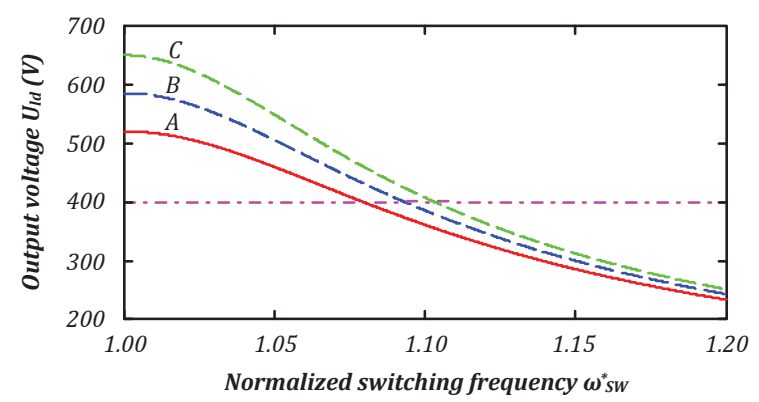

Fig. 6. Regulation characteristics of the case study converter with the VFC.
A set of regulation characteristics were obtained using (8) for the case of the PSM control (Fig. 7) for operating points in the buck mode. They have a similar dependence on the phase shift angle, while the output voltage at the zero angle is different. At the same time, theoretical voltage in the normal mode for point $D$ equals $455 \mathrm{~V}$ and thus control angles at each curve have to be taken at this level. Further, they will be compared with those obtained from the experiment. This control method does not suffer from sensitivity to the load resistance. However, the losses will lead to a lower output voltage. Thus, experimental values of the phase shift angle have to be lower than those calculated theoretically.

\section{Experimental Verification}

The experimental prototype was tested to verify theoretical predictions. The test bench includes the digital phosphor oscilloscope Tektronix DPO7254 equipped with high-voltage differential voltage probes Tektronix P5205A and the Rogowski coil current probe PEM CWTUM/015/R for capture of operating waveforms.

Experimental waveforms were obtained at the experimental prototype for operation point $C$, i.e. at maximum input voltage, for both control methods. Our experiment shows that the switching frequency equal to $114 \mathrm{kHz}$ is required in the case of the $\mathrm{VFC}$ to obtain $400 \mathrm{~V}$ at the output of the converter, when $50 \mathrm{~V}$ voltage is applied to its input. The phase shift angle equal to $84.6^{\circ}$ was needed to perform the same voltage step-down in the case of the PSM.

Fig. 8 presents the current and voltage of one inverter switch $\left(S_{3}\right)$ for both control methods - the VFC (Fig. 8a) and the PSM (Fig. 8b). In the first case, the switch handles negative current and thus can be turned on with zero voltage switching (ZVS) if proper deadtime is used to achieve body diode conductivity in the beginning. Since the transformer current is high before the turn-off transient, the ZVS turn-off assisted with leakage inductance is possible if deadtime is used and selected properly to ensure switch output capacitance recharge. In the second case, the ZVS can be achieved with proper deadtimes with the difference that the leakage inductance assists ZVS turn-on, while ZVS turn-off is ensured with a body diode.

Fig. 9 presents the voltage and current of the input side winding of the isolation transformer for both control methods. In the case of the VFC (Fig. 9a), the transformer voltage is rectangular without zero level intervals, while in the case of the PSM (Fig. 9b), it features zero level intervals at the input

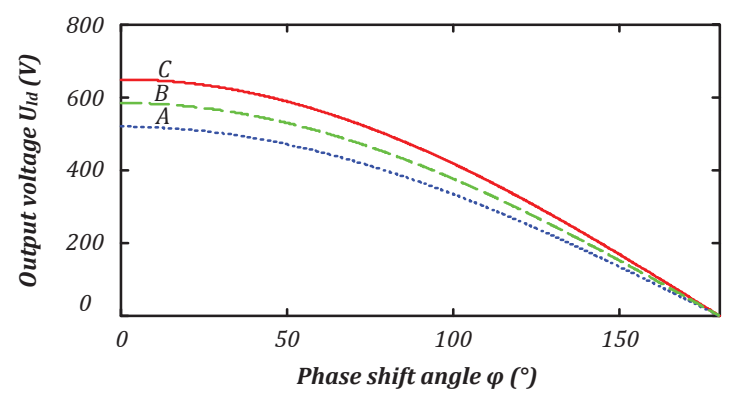

Fig. 7. Regulation characteristics of the case study converter with PSM. 
side winding. However, the output side winding voltage is rectangular without zero level intervals and synchronized with zero crossing instants of the transformer current. Duration of the zero level intervals at the input side winding is directly proportional to the phase shift angle $\varphi$.

Fig. 10 presents the voltage and current of diode $D_{2}$ of the VDR. The VDR diodes feature ZCS operation assisted with the leakage inductance of the isolation transformer for both control methods. It is evident that both control methods properly exploit soft-switching possibilities of the series resonant converter.

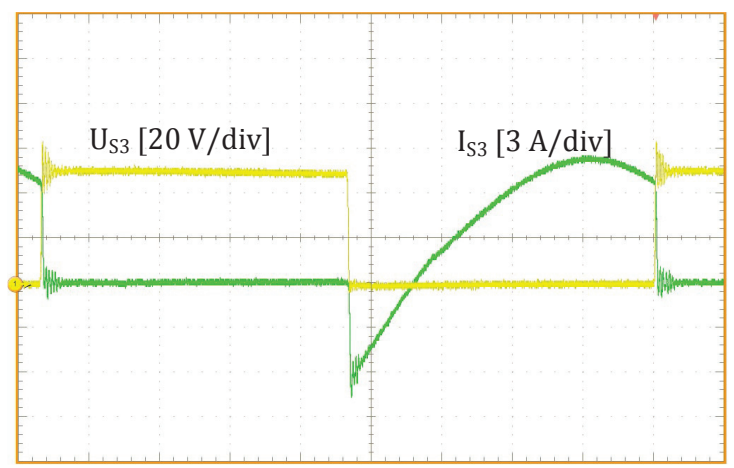

(a)
Regulation characteristics of both of the buck mode realization methods measured are presented and compared with theoretical predictions in Fig. 11. Fig. $11 a$ illustrates the frequency to be applied to the converter if the input voltage is higher than the rated one. Apparently, the switching frequency measured is higher than that predicted theoretically. It is mostly due to higher losses that result from a lower quality factor, which requires higher frequency for the same voltage step-down. However, the frequency regulation range is still narrow, as it was predicted theoretically. Similarly, Fig. $11 b$ illustrates the inverter phase shift angle to be used when the

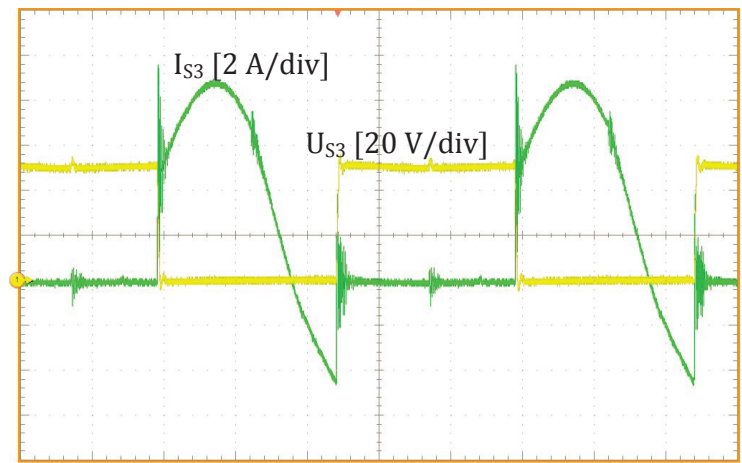

(b)

Fig. 8. Experimental waveforms of the switch $S_{3}$ of the inverter: a) VFC in time scale $1 \mu \mathrm{s} /$ div; b) PSM in time scale $2 \mu \mathrm{s} /$ div.

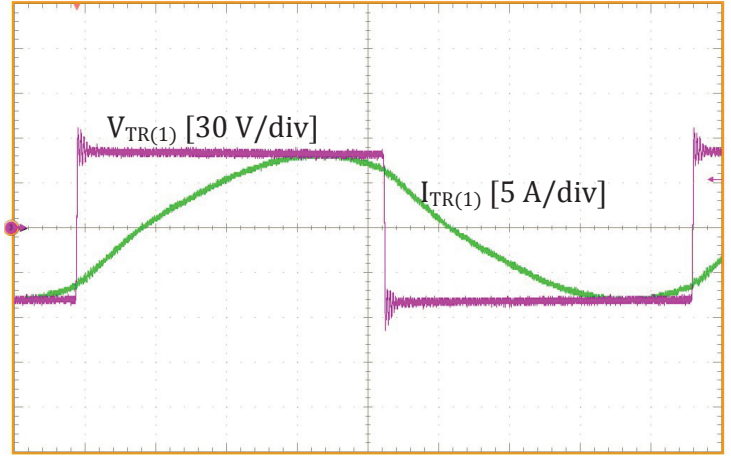

(a)

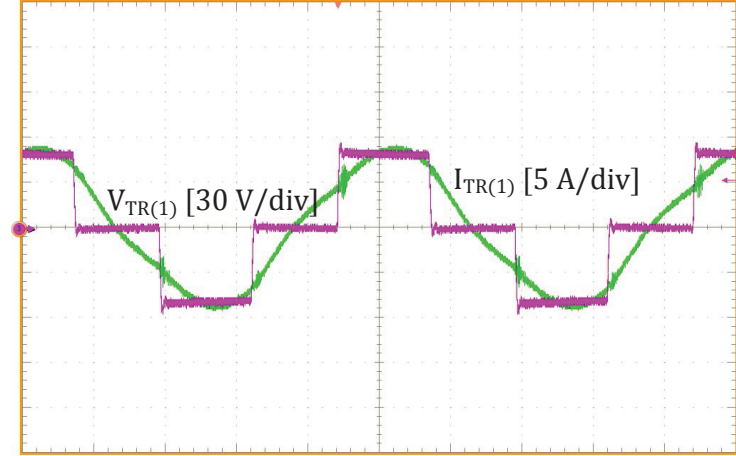

(b)

Fig. 9. Experimental waveforms of the transformer primary voltage and current: a) VFC in time scale $1 \mu \mathrm{s} /$ div; b) PSM in time scale $2 \mu$ s/div.

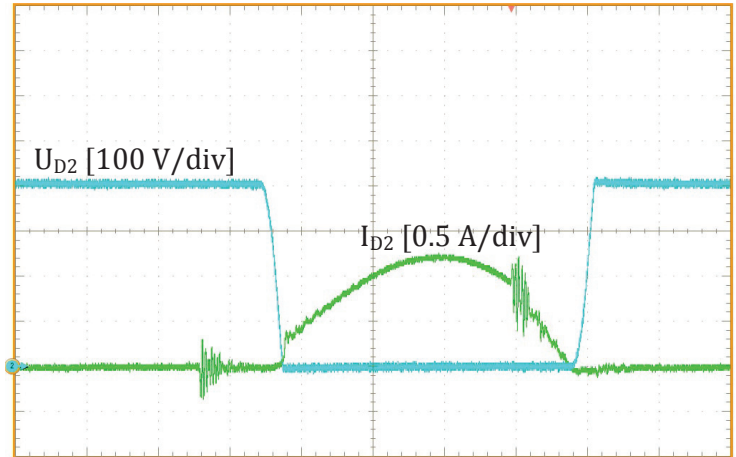

(a)

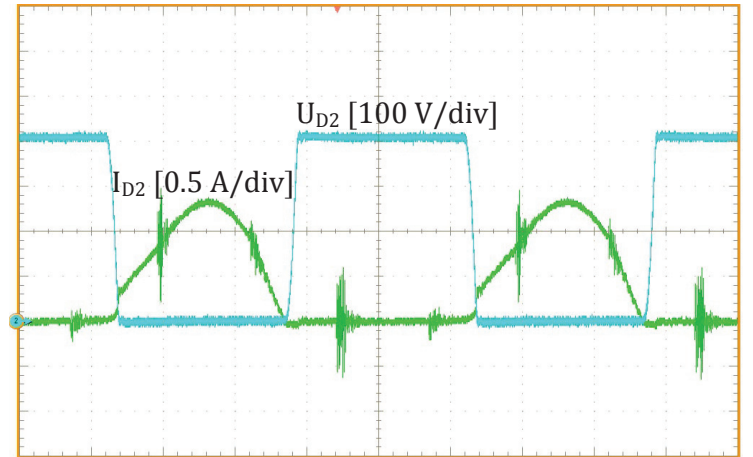

(b)

Fig. 10. Experimental waveforms of the VDR diode $D_{2}$ : a) VFC in time scale $1 \mu \mathrm{s} /$ div; b) PSM in time scale $2 \mu$ s/div. 


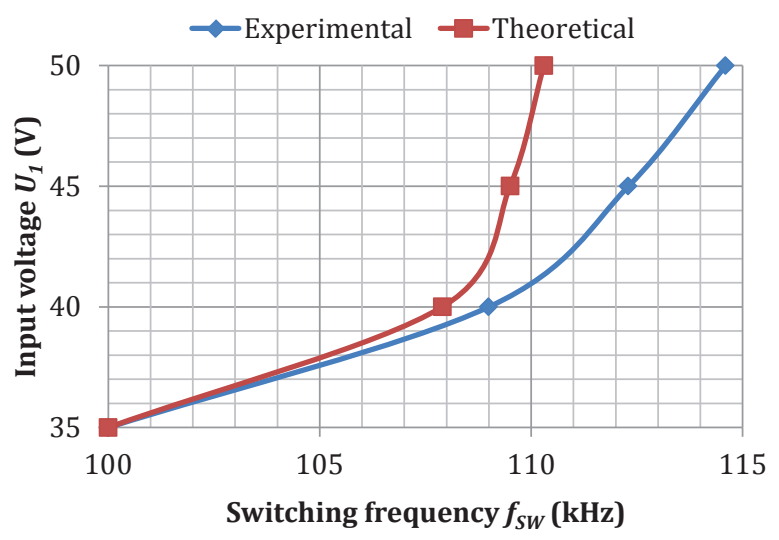

a)

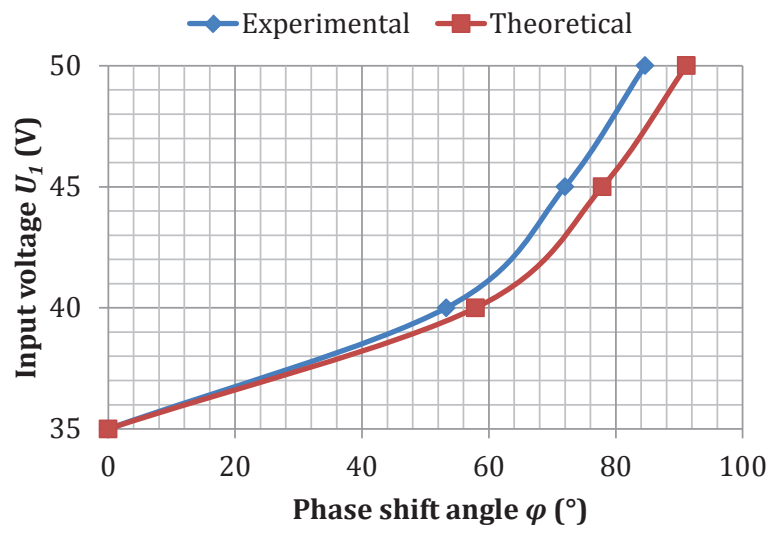

b)

Fig. 11. Regulation characteristics in the buck mode for VFC (a) and PSM (b).

input voltage is higher than $35 \mathrm{~V}$. These results are also in good agreement with the predictions. The converter requires a slightly lower phase shift angle than predicted theoretically, since the power loss in the converter leads to additional voltage step-down.

\section{CONCLUSIONS}

In this paper two different buck mode control methods for the galvanically isolated qZS based series resonant DC-DC converter were presented and verified. Both of them allow realization of the buck mode in the qZS based series resonant DC-DC converter with the VDR.

In the given case, an input voltage rise by more than $40 \%$ over the nominal value was considered. It means that the regulation range of the converter can be easily doubled if the voltage step-up in the boost mode is limited by $1: 2$. Moreover, both methods show an ability to step the voltage even further down. In other words, the combination of buck and boost operating modes allows the design of the qZS converter with an ultra-wide input voltage range.

Among the two buck mode realization methods, the PSM seems to be superior over the VFC. The PSM does not depend on the load resistance and provides constant switching frequency. It avoids poor controllability at light loads typical for the VFC. Moreover, in PSM the converter power loss results in a smaller phase shift than necessary for the voltage step-down as compared to the phase shift angle calculated theoretically. At the same time, the converter power loss leads to higher switching frequency than that calculated theoretically in the case of the VFC. This is due to the high sensitivity of the VFC regulation characteristic to the quality factor of the converter that depends on the load resistance and indirectly on the converter power loss. Due to power losses in the converter, higher frequency is required in the VFC than that theoretically predicted. At the same time, smaller phase shift angle will be required to achieve the nominal output voltage level in the PSM.

Finally, soft-switching operation of the converter can be maintained for both of the buck mode realization methods.

\section{ACKNOWLEDGMENT}

This research work has been supported by Latvian Council of Science (Grant 416/2012) and by Estonian Ministry of Education and Research (project SF0140016s11).

\section{REFERENCES}

[1] Yuan Li; Anderson, J.; Peng, F.Z.; Dichen Liu, "Quasi-Z-Source Inverter for Photovoltaic Power Generation Systems", Twenty-Fourth Annual IEEE Applied Power Electronics Conference and Exposition APEC 2009, pp. 918-924, 15-19 Feb. 2009.

[2] Vinnikov, D., Roasto, I., Zakis, J., Strzelecki, R. "New Step-Up DC/DC Converter for Fuel Cell Powered Distributed Generation Systems: Some Design Guidelines," Przeglad Elektrotechniczny (Electrical Review), vol. 86 (8), pp. 245-252, 2010.

[3] Vinnikov, D.; Roasto, I., "Quasi-Z-Source-Based Isolated DC/DC Converters for Distributed Power Generation," IEEE Transactions on Industrial Electronics, vol. 58, no. 1, pp. 192-201, Jan. 2011.

[4] Zakis, J.; Vinnikov, D.; Bisenieks, L. "Some Design Considerations for Coupled Inductors for Integrated Buck-Boost Converters," $3^{\text {rd }}$ International Conference on Power Engineering, Energy and Electrical Drives POWERENG 2011, pp. 1-6, 2011.

[5] Honnyong Cha; Peng, F.Z.; DongWook Yoo, "Z-source resonant DCDC converter for wide input voltage and load variation", International Power Electronics Conference (IPEC'2010), pp. 995-1000, 21-24 June 2010 .

[6] Zakis, J.; Rankis, I.; Liivik, L. "Loss Reduction Method for the Isolated qZS-based DC/DC Converter," Electrical, Control and Communication Engineering, vol. 4, pp. 13-18, 2013

[7] Vinnikov, D.; Zakis, J.; Liivik, L.; Rankis, I. "qZS-based Soft-switching DC/DC Converter with a Series Resonant LC Circuit," Energy Saving. Power Engineering. Energy Audit, vol. 114, no. 8-2, pp. 42 - 50, 2013.

[8] D. Vinnikov, I. Roasto, and T. Jalakas, "New step-up DC-DC converter with high-frequency isolation," in Proc. 35th Annu. Conf. of IEEE Ind. Electron. Soc. (IECON), 3-5 Nov. 2009, pp. 670-675.

[9] M. Egorov, D. Vinnikov, R. Strzelecki, and M. Adamowicz, "Impedance source inverter based high-power DC-DC converter for fuel cell applications," in Proc. of 8th EEEIC Int. Conf. on Environment and Elect. Eng., pp. 1 -4, 10-13 May, 2009.

[10] Kazimierczuk, M.K.; Wang, S., "Frequency-domain analysis of series resonant converter for continuous conduction mode," IEEE Transactions on Power Electronics, vol. 7, no. 2, pp. 270-279, Apr 1992.

[11] Vandelac, J.-P.; Ziogas, P.D., "A DC to DC PWM series resonant converter operated at resonant frequency," IEEE Transactions on Industrial Electronics, vol. 35, no. 3, pp. 451-460, Aug 1988.

[12] Sooksatra, S.; Lee, C.Q., "PWM-controlled SRC with inductive output filter at constant switching frequency," IEEE Transactions on Power Electronics, vol. 7, no. 2, pp. 289-295, Apr 1992. 